Interview with Samantha

Frost on 'The Attentive

Body': Epigenetic

202I, Vol. 27(3) 87-10I

(C) The Author(s) 2021

(c) (i)

Article reuse guidelines: sagepub.com/journals-permissions DOI: $10.1177 / 1357034 \times 211028638$ journals.sagepub.com/home/bod Processes and Self-formative (3)AGE Subjectivity

\title{
Tomoko Tamari
}

Goldsmiths, University of London

\begin{abstract}
The interview is a follow-up from Samantha Frost's article, 'The Attentive Body', in Body \& Society 26(4). Tomoko Tamari invites Frost to explore her interest in 'biocultural creatures', with its focus on 'bodies' responsive self-transformation' in epigenetic processes, and unfolds Peirce's account of the index for understanding meaning-making in biological processes. Tamari also introduces Katherine Hayles's notion of 'cognitive nonconscious' to raise the question of the possible theoretical and mechanical similarities/discrepancies between epigenetic processes in organisms and the meaning-making process in computational systems. Drawing on Jacob von Uexkull's notion of 'umwelt' and introducing Yoshimi Kawade's remarks on a living being's subjective orientation in environments, a further question about 'intention' and 'subjectivity' enables Frost to further unpack her notion of 'the attentive self' and discuss its relation to 'intentionality' and 'referentiality' in epigenetic processes. Finally, Samantha Frost mentions her current projects on the connection between 'attention-as-responsive-self-transformation' and 'mode-of-living-as-form-of-life'.
\end{abstract}

\section{Keywords}

computational media, epigenetics, semiotics, subjectivity, umwelt

Samantha Frost's article, 'The Attentive Body: How the Indexicality of Epigenetic Processes Enriches Our Understanding of Embodied

Corresponding author: Tomoko Tamari

Email: t.tamari@gold.ac.uk

B\&S Online Forum: https://www.theoryculturesociety.org 
Subjectivity', in Body \& Society 26(4) was originally published in December 2020. The biosemiotics view of the living body presented in the article leads us to go beyond the mechanical view of organism functionality and formation process of subjectivity. This challenge asks us to combine biology and semiotics in order to explore the complex mechanism of meaning-making in organisms and to capture 'the attentive body' and 'embodied subjectivity'. The article argues that the concept of the attentive body helps us make a bridge between the body as matter and mind/subjectivity which natural science usually excludes from its domain.

Tomoko Tamari (TT): You mentioned that this article was germinated at the 'Matters of perception: Objects and materialities of affects' seminar at the Kent Summer School in Critical Theory (2016) and developed through participating in several conferences (2016-2017) as well as being stimulated by conversations with many colleagues. Could you say a little more about your initial point of departure and how your ideas have developed over time?

Sam Frost (SF): In Biocultural Creatures, my work was focused on how, precisely, we might think what a person is if there is no part of their biological body that has not been materially and socially cultured. My second discipline training in molecular and cellular biology had made it pretty clear to me that there are no purely biological phenomena - down to their tiniest parts, bodies are biocultural or biosocial. And yet, many of the categories, concepts, figures and logics that we use to think about subjectivity rely in some way on a qualitative distinction between biological processes and $\mathrm{mind} /$ culture/meaning. For me, the concepts of embeddedness, interaction, intra-action and entanglement, while capturing or representing a state of being, did not give me enough texture or purchase for thinking deeply and in conceptual detail about how biocultural processes in an embodied self proceed, or what the logic of those processes might mean for many of the concepts that are cognate with our thinking about embodiment and subjectivity. So, Biocultural Creatures was my effort to elaborate the concepts and figures of movement that I needed to think about the biocultural: how should we think about the relationship between energy and matter when considering how bodies work? What counts as a body or self when the boundaries of the body and self are porous? How does the notion of a biocultural creature help us think around biological or 
environmental determinism? What understandings of time, temporality and history do we need when we think of humans as biocultural creatures?

While I did manage to elaborate concepts that help us think with the notion of the biocultural, I did not explore meaning or meaningmaking. I foregrounded the many ways that bodies are responsive to their lived worlds, but I did not explore the quality of that responsiveness, the quality of the forms of responsive self-transformation. So the challenge posed to me by my own thinking was to figure out how to articulate scientifically grounded insights about responsive self-transformation in conceptual and theoretical terms that might be useful for a theory of subjectivity. The seminar I taught at the Kent Summer School in Critical Theory was coordinated by Connal Parsley and Maria Drakopoulou and was a timely opportunity for me to begin thinking about how to articulate that question about quality and meaning. I had a sense that the notion of the biocultural would require a displacement of language and representation - not their dismissal but instead a decentring that might allow other dimensions of a biocultural self's engagement with the world to emerge as foci of analysis. Consequently, in the seminar, we worked through a range of texts that portray forms of perception that are not primarily linguistic or visual: we considered proprioception, the perception of gravity, hearing and acoustics, blindsight, the immune system, animal perception, heliotropism, movement in architectural space, extended cognition, synaesthesia. The seminar was basically a stint of intellectual calisthenics to loosen up the conceptual strictures of dominant understandings of perception so that I could then play around with different possibilities for what perception might be and where it might take place.

It takes me forever to develop an idea and write it out in a way that satisfies me. So after the seminar, I wrote a draft of the 'Attentive Body' essay and then reworked it for a couple of years until it said what I needed it to say. I was lucky to be able to present versions of it around and about - and people's questions and comments were tremendously helpful in alerting me to where the ideas were fuzzy, where I needed to be bolder and so on.

TT: You introduced Michelle Jamieson who argues that 'to capture theoretically the entanglement of life and meaning', it is important to consider 'how biological matter becomes saturated with the effects of 
social and political life' as well as 'how biological processes generate meaning or knowledge out of those effects'. Could you say a little more about why Jamieson's remarks are important for your approach? And why you particularly chose 'epigenetics processes' as the main field for your theoretical focus on the 'attentive body'?

$S F$ : There is a slew of scholars who explore how what I call biocultural creatures are responsive in their bodies to the social and material dimensions of their lived worlds - I'm thinking here, just to name a few, of Elizabeth Grosz, Elizabeth Wilson, Anne FaustoSterling, Arun Saldanha, Nikolas Rose, Michelle Murphy, Deborah Youdell, Zakiyyah Iman Jackson, Maurizio Melonio, Rachel Lee. It is a really rich field of scholarship. What I particularly liked about Jamieson's elaboration of Georges Canguilhem's philosophy is her suggestion that the responsive self-transformation we can see in bodies is not a mere mechanistic reaction but instead is a form of perceptual cognition and meaning-making. In her argument, it is not just that meaning is imposed on bodies or absorbed by them in ways that directly or indirectly affect biological processes but also that a body's responsiveness to those impositions and absorptions is in itself meaningful. For me, Jamieson's argument was a means to connect conceptually work in social and political theory on how bodies are affected by politics with work in zoosemiotics and biosemiotics on the processes by which non-human living creatures generate meaning in the course of living.

To think about biological processes as meaningful for the creature in whom they unfold is to decentre or dislocate our sense of where the self is - or perhaps to disperse a sense of self beyond linguistic subjectivity and the ley lines of neurologically mediated perception. I ended up thinking about these questions through the phenomenon of epigenetic processes precisely because I am interested in thinking about bodies' responsive self-transformation. In my view, to be a biocultural creature is to constantly compose, decompose and recompose; in those processes, genes and proteins are of course key, as are epigenetic processes. In lay understandings of genetics, there have conventionally been the two poles of determination and randomness: determination by genes and transformation via stochastic mutation. Epigenetic processes blow apart that framework because they are processes by which bodies shift the ways they compose, decompose and recompose in response to their experiences of their lived worlds. 
What I find interesting about epigenetic processes is that they are neither determined nor random. Instead, they evince a patterning that is linked somehow with a rich mix of material and social provocations and experiences; they are patterned forms of responsive transformation that are evoked and have effects across regulatory systems and across temporal scales.

Although I haven't done the analysis myself, I think you could probably trace out the ways in which immune system processes are also forms of attention and meaning-making - I'm thinking here of Pradeu and Carosella's (2006) account of the immune system not as a strict self-other monitoring system but instead as a form of attunement to things that support or undermine continuity of biological functioning. I think this could be figured as a form of meaningful perception, for sure. I think it is equally possible to think in terms of meaning-making when considering the microbiome, social neuroendocrinology and mirror neurons.

Ultimately, I am interested in the ways that meaning-making could occur at different scales and in different systems of the body, such that what we call subjectivity has many layers and textures - including the linguistic but also including the temporal and physical scales bound up with epigenetic processes. I don't know that I would aim for a completely synthetic and integrated account of subjectivity; I think the effects of these systems and processes on one another are uneven and unpredictable. However, I do think there are political, ecological, social and personal insights to be drawn from an understanding of the self that includes the meaning-making selftransformative responsiveness of these different biological/biocultural processes - such an account could help us rethink power relations, inequality, stress, discrimination, green space, urban space, nutrition, pollution and toxins .... The aspiration here is similar, perhaps, to the transversally complex account of mental health that Rose, Birk and Manning recently articulated (2021).

$T T$ : In the section on Indexical Signs, you argue that 'arbitrary linguistic convention has blinded us to other forms of signification in which there is a tighter relationship between a sign and its object'. An object can work as a sign. You emphasize that there can be a clear 'causal' relationality between sign and its object/referent and connection between object as a sign and the person. You also support Eduard Kohn's criticism about anthropocentrism which can restrict 
an account of non-linguistic signification. Hence, rather than applying 'the intertwinement of post-structuralist psychoanalysis and linguistics', you find Charles Sanders Peirce's semiotics to be useful in accounting for 'the non-symbolic, non-arbitrary relationship between sign and object in mementos' (Frost, 2020: 9, emphasis added). Sign systems studies has developed with and been influenced by structuralism. 'One of the central tenets of structuralism concerns the relational nature of a system like the system of language' (Kull et al., 2011: 5-6). According to Kull et al., 'structuralism in linguistics - has been an important step in the formation of a semiotic approach that looks for relations of signification even beyond the human domain of social structures' (Kull et al., 2011: 5-6, emphasis added). Here, it seems that 'relationality' can be a key explanatory term for both your argument and structuralism. I wonder if you could explain more about your view of semiotics and its relation to linguistic structuralism?

$S F$ : There is a lot going on in this question! It has been a long time since I studied this, but my understanding of structuralist theories of language is that they privilege analytically signs that have an arbitrary relationship to what we might call the real world and whose meanings are thus generated through the differential values manifest in systemic relations between the signs in a linguistic system. Poststructuralist theories of language challenged structuralism by pointing to the instability and indeterminacy of the sign values and relations - what seems to anchor a system of signs does not actually anchor it well; the system is open, history and personality make meaning exceed the structured terms of the system. I can see how the structuralist focus on systemic relations between signs could provide a template that biosemioticians could use to lay on maps of biological processes: one could say 'these biological processes constitute a structured system and thus we can think of these biological processes as constituting a structured sign system'. And indeed, although I have not read deeply in the biosemiotics literature, this could be said to be the way that some scholars in biosemiotics proceed.

For me, though, the insights of post-structuralism remain pertinent, especially when thinking about biological processes. If bodies are relatively and selectively porous, then they are not closed systems; if we are biocultural creatures, then we are open systems, 
layered systems, with transcalar histories that affect how our biological processes unfold. The intrinsic and necessary openness of biological processes is in tension with a formally structural account of sign processes. Furthermore, my sense is that structuralist accounts of language portray linguistic subjects as relatively passive - it is not that you speak a language but rather that, as they say, the language speaks you. My understanding of the distinctive challenge posed by Peirce's theory of language is that it is concerned not primarily with the relations between abstract or ideal signs but rather the relations between signs, referents and interpretants - the latter being the creatures who use signs and make meanings with them as they navigate the social and material world. And what I find particularly interesting is his sense that the interpretant is interpreting, that is, is doing work, making-meaning, acting. So for me, because I am particularly interested in concepts that do not render the body passive and merely mechanistically reactive, but instead active and transformatively responsive, I would not deploy a structuralist template to think about biosemiosis. If we are mapping the processes by which bodies engage and use their lived worlds, I think the processes of biosemiosis are just messier, more layered and more open to disturbance than structuralism can allow. Since biological processes concern not just the world at a distance but instead taking the world in - absorbing it, transforming while transforming it, excreting it - I would resist trying to fit Peirce's account of language into a structuralist framework. In the end, what drew me to Peirce's account of the index is the sense he has of contact with the world of objects and people and of labile meaning-making in the process of living.

TT: You mention that signs are not arbitrary, but more determinant. The view could lead to the idea that meaning-making processes in organisms are based on sign-processing, rather than symbol-processing. What strikes me is that there are some similarities here with debates in media theory involving those who are working on computer information in digital humanities. Katherine Hayles, for example, explores similar functions between machine cognition and biological cognition to develop her notion, 'cognitive nonconscious' (Hayles, 2017: 2), which includes technical as well as organic cognizers. In her discussion, she thinks that biosemiosis approach is useful to understand meaning-making processes in both machine and organic cognition. She is of course fully aware of the huge 
differences in embodiment between computational media and biological organisms. Computers do not evolve, like organisms which have the imperative to survive, but they accomplish their 'given' purpose in the existing environment. She further explains that computers work based on "if/else" command: If a certain set of criteria are present, do the following; if not, then do something else'. For her, this command can be understood as computational semiosis which implies 'sign-exchanges' (Hayles and Sampson, 2018: 63)

More importantly, she explains that Jesper Hoffmeyer uses the Peircian model of sign/object/interpretant in developing the idea of biosemiosis (Hayles and Sampson, 2018: 62-63) and emphasizes the importance of the 'interpretant' who is the "someone" for whom the sign-processes have meaning - and the ground level of meaning for lifeforms is survival' (Hayles and Sampson, 2018: 63).

You also explore who might be the interpreter ('a sign of a prior sign') of a sign in biological processes (Frost, 2020: 26). You argue that 'the indexicality of epigenetic processes predicates the body as both originator and interpreter of semiosis', since 'the indexical manner in which a body's epigenetic responses to its experiences generate physical transformation in chromatin' (Frost, 2020: 26, emphasis added).

In this sense, one might consider that there might be a mechanical difference between organisms with/in 'the body' and computers (without the fleshed body). Given such possible discrepancy, I wonder how you consider the theoretical relationship/difference between your understanding of epigenetic process in organisms and the meaning-making process in computational systems?

$S F$ : You are right that I am working within a framework in which the category of 'sign' is more capacious and inclusive of more kinds of sign than the category of 'symbol'. And you are right that, drawing on Peirce's argument about indexes, I argue that indexes are signs that have a more determinant relation to their referents than, say, linguistic symbols do. I hedge my answer a little bit here because if we pluralize the kinds of signs that are possible to include in an analysis - icons, indexes, symbols, for instance - and if those different kinds of signs have different kinds of relations to their referents, then we have to consider carefully the conditions in which we speak of 'signs' in general, 'signs' without a qualifier. 
That said, I have to confess that I do not know much at all about computational systems, artificial intelligence or the digital humanities. So I can only address your question from a very thin knowledge base. For me, the key point in your question is Hayles's recognition that 'the ground level of meaning for lifeforms is survival'. This idea of a creature for whom life is at stake in its engagement with its lived world - this suggests to me that perhaps the distinction in question is not one between sign processing and signal processing but instead between sign/signal processing and meaningmaking, that is, interpretation. I am unsure whether sign-processing and meaning-making are the same thing. Hayles is clear that signal processing is linear in its logic. And to reference your earlier question, the notion of sign-processing seems structural or systemic in that it concerns inferential relations between signs. But interpretation and meaning-making seem more personal in the sense that there are stakes, a sense of value, judgement, intimacy or involvement. For instance, when I read the work of Jakob von Uexkull (2010) or Georges Canguilhem $(1991,2008)$ - both of whom are key thinkers for scholars who study biosemiosis - I notice that whereas they are often portrayed as discussing the ways that perceptual processes generate a milieu, the details of their arguments concern not mere perception but instead use and activity: what makes something meaningful is the remembered and anticipated use of the thing - whatever it is. I suppose that in this context, I consider epigenetic processes as a kind of use, or as Agamben might say, in The Use of Bodies (2015), a using of the self in the process of using the world. Once you shift to thinking about epigenetic processes as indexical forms of attention, and then you predicate the living creature as a whole as that which pays attention, then you are no longer talking only of the mechanics of molecular scale processes inside a body; you are talking about a living creature whose various forms of meaning-making are bound up with their persistence in living, with their living their lives.

But if I keep thinking through your question, I suppose it is possible that if AI systems could become complex enough at navigating and parsing social and material worlds, the distinctive logic of the mediated inferential patterns by which epigenetic processes function as indexical forms of attention and meaning-making might be 
conceptually useful, even if the AI system's existence is not at stake. A provocative question.

TT: You draw attention to Yoshimi Kawade's biological function of a molecule (Frost, 2020: 15). Kawade was strongly influenced by Jacob von Uexkull's notion of 'umwelt'. Kawade considered that 'signs and their meanings start as biological relations that emerge together in the course of life, 'as living beings live with their own subjectivity, interacting each other and projecting their subjectivity onto the environment' (Kawade, 1998: 288 cited in Favareau and Kull, 2020: 205-206). Here, subjective orientation is important. We can understand, thus, meaning-making processes are determined by a subject with a specific world view. For Kawade, 'All living things, including single-celled organisms, have a certain degree of freedom from physical causality to choose their actions with intentions to fulfill their purpose' (Kawade, 2013: 367, emphasis added). This could raise the question - could we understand a single cell organism as an agentic entity as having intentions? I wonder that if we can follow his remarks and consider even single-celled organisms have intentions, it might be possible to consider whether or not a single organism has subjectivity? What do you think and how might we better understand subjectivity in an organism?

$S F$ : You're right that I find Kawade's research a provocative resource; the fact that he is well-versed in laboratory science makes his work really useful to me. I think perhaps my training as a political theorist makes me more wary than he is of terms like purpose and intentions. For me, the notion of purpose is too redolent of the notion of teleology and actually undercuts the indeterminacy of action that Kawade is otherwise interested to highlight. But the notion of intention is one that I draw on in my 'Attentive Body' essay, although it is important to note that I use it differently than Kawade uses it - and thus the way you use it in your question.

In my article, I use the notion of intentionality rather than intention. In philosophical terms, intentionality denotes an orientation towards a specific something when we engage in an action, an orientation such that our action is 'about' the thing. In other words, in this inflection of the term, an action is said to be intentional when it is referential. Another meaning of the term, which is the second noted above, concerns when a subject posits him- or herself as an agent, imagines doing a particular something and then sets out to do it. This 
version, then, turns on both an explicit anticipatory notion of the self as agent of a specific action and a sense or experience of wilfulness in relation to realizing an anticipated action. While I am quite happy to attribute the first 'referential' version of intentionality to singlecelled organisms, I am more reluctant to attribute to them this second version, in part because the latter requires more complex forms of mentation and a more refined sense of self in a temporally complex field of action than I think single-celled organisms can muster.

Part of my argument in the 'Attentive Body' article is that epigenetic processes are intentional in that they are referential, even if that referentiality is somewhat mediated. In such biological processes, a self ends up being functionally predicated even if not consciously held as an idea. Is a self the same thing as a subject? This is a question that is up for debate. But as of now, in my view, because intentionality-qua-referentiality and a functional sense of self are integral to many biological processes, I would venture to affirm that single-celled organisms have a functional sense of self, even if I would not yet go so far as to say that they are subjects. For creatures who are more than single-celled - bigger, more complex - I would not hesitate to attribute subjectivity to them. Of course, it would not be what we think of as linguistic subjectivity .... I suppose that part of what I am trying to do in my work is elaborate an account of extralinguistic subjectivity, and it is not all worked out yet.

What could the pieces of the argument that I have developed so far mean for a theory of subjectivity? Mostly that subjectivity is deeply layered and textured, striated and temporally complex - more so than we have captured in even our richest theoretical pictures. When humans come into linguistic subjectivity, all those other facets of attention and responsive self-transformation - whether epigenetic, immunitary, microbiomic or endocrinal - subtend that more selfconsciously or explicitly imagined and experienced sense of self. The notion of the attentive body that I develop in the article is not supposed to supplant other understandings of the self and subjectivity. It is more an effort to capture conceptually and in theoretical terms the fact that, in addition to language, psyche, affect, identity, movement and extended cognition, there is this further dimension of the self that is attentive and engaged, that is not managed by the extended neurological system but nevertheless exhibits intentionality or referentiality in processes that shape the subject's growth and 
capacities. In all likelihood, this attentive dimension of the self that I draw out modulates the other dimensions in various ways - although I have not yet done the work to specify that.

TT: Finally, could you let us know more about your research project at the Illinois Program for Research in the Humanities (IPRH)-Mellon Biohumanities Research and what you are working on now, as well as how you want to develop it in relation to possible future research projects?

$S F$ : The IPRH-Mellon Biohumanities Research Initiative was a two-year interdisciplinary research program I directed at the University of Illinois, Urbana-Champaign, funded by the Andrew W. Mellon Foundation and hosted by the Illinois Program for Research in the Humanities - which is now known as the Humanities Research Institute. The purpose of the initiative was to explore the contours, questions and methods that animate the emerging field of biohumanities. To my mind, the work of the biohumanities is to develop accounts of human being that can both accommodate the wealth of contemporary scientific research and provide conceptually rich accounts of humans, their behaviours and their cultures. Thus, the biohumanities is distinguished from, say, science and technology studies, by its critical and creative appropriation of findings in the biological sciences for the purpose of reimagining and reconfiguring our sense of human being and of the meaning and significance of human undertakings.

Within the Biohumanities initiative, rather than pursuing one specific research project, the various fellows conducted a variety of research projects, participated in an ongoing seminar and exchanged ideas with a range of visitors whose research falls near or within the purview of the biohumanities. We were trying to figure out what the biohumanities might be, what methods would be appropriate to the field - basically, how to talk about and do it! While I directed the initiative over the two-year period, I worked through the argument of the attentive body article and traced the outlines of the larger project of which it is the foundational part. In the larger project, I am really trying to figure out and articulate this theory of the subject and what it might mean for our understanding of politics. Now that I have figured out the attentive body argument, I am working through the next step.

The conundrum that structures the next piece of the project is that whereas a lot of work on the biocultural or the biosocial has disrupted the boundaries of the self and worked to articulate a composite, 
hybrid phenomenon, the lived world or the environment that is construed as occasioning or generating that composite hybrid is still conceived as an external spatial field. While the conceptual fusion of body and world has resulted in a differently rendered concept of a living creature, that fusion has not had a similarly transformative effect on the notion of the lived environment. The latter remains true to its history as a spatial concept; the world that provokes responsive self-transformation remains bound to a spatial schematic. And of course, if we consider the factors that affect epigenetic processes, they are not only or primarily spatial - they are imaginative, felt, anticipatory, remembered, temporally complex. So the question animating this next part of my project is: what concepts do we need to be able to think about the lived world or the environment not primarily as a spatial externality with which a biocultural creature has a selftransformative, self-constituting relation?

As I intimated above, for me, the clues are in Uexkull's and Canguilhem's notion of use - remembered and anticipated use as constitutive of meaning. In The Use of Bodies, Giorgio Agamben deploys the concept of use as a means to side step the question of relation. For Agamben, as for several other contemporary theorists, relation as a concept predicates two originally separate and distinct entities whose gap requires the relation as a copula or bridge. Agamben suggests that the sundering performed by the notion of relation can be foreclosed by the notion of use, which implies not only an intimacy between a (using) creature and a (used) thing but their mutual (self) transformation through the process of using. Then, through a series of theoretical moves, Agamben argues that habitual use is a form of life - and what I like about this formulation is that it is not primarily spatial! It allows us to say that what attentive bodies pay attention to is a mode of living, not a spatial field of forces.

I am currently working through this problematic. And as luck would have it, I have entered into a collaboration with two Chicago area artists - Sara Black and Amber Ginsburg. With a collaborative fellowship funded by the Mellon Foundation and hosted by the University of Chicago's Gray Center for Arts and Inquiry, we are exploring the connection between attention-as-responsive-selftransformation and mode-of-living-as-form-of-life. We are just now beginning our project in earnest and are focusing our attention on a combination of tree ecologies, food hedges and environmental justice 
concerns. Thinking with Sara and Amber in collaboration, digging around in dirt and engaging actual neighbourhoods is a very different way for me to work but is also super fun.

And once I have figured out how to explain all these ideas well, then I will trace how they might require us to retool concepts we use to think about politics. Small things.

\section{References}

Agamben, Giorgio (2015) The Use of Bodies. Palo Alto, CA: Stanford University Press.

Canguilhem, Georges (1991) The Normal and the Pathological. Brooklyn, NY: Zone Books.

Canguilhem, Georges (2008) Knowledge of Life. New York, NY: Fordham University Press.

Favareau, Donald and Kull, Kalevi (2020) Chapter 14: A biosemiotician of the first generation. In: Youichiro Iwakura, et al. (eds) Seimeitoha Nanika wo Toitsuzukete - Bunshiseibutugaku no Sakie [What is the Life - Beyond Biosemiotics]. Kyoto: Kyoto Daigaku Gakujyutsu Shuttpankai (Kyoto University Press), pp. 197-223.

Frost, Samantha (2020) The Attentive Body: How the indexicality of epigenetic processes enriches our understanding of embodied subjectivity. Body \& Society 26(4): 3-34.

Hayles, N Katherine (2017) Unthought, the Power of the Cognitive Nonconscious. Chicago, IL: The University of Chicago Press.

Hayles, N Katherine and Sampson, Tony D (2018) Unthought meets the assemblage brain. Capacious: Journal of Emerging Affect Inquiry 1(2): 60-84.

Kawade, Yoshimi (2013) The origin of mind: the mind-matter continuity thesis. Biosemiotics 6: 367-378.

Kull, Kalveni, Emmeche, Claus and Hoffmeyer, Jesper (2011) Why biosemiotics? An introduction to our view on the biology of life itself. In: Towards a Semiotic Biology: Life Is the Action of Signs. London: Imperial College Press.

Pradeu, Thomas and Eduardo, Carosella (2006) The self model and the conception of biological identity in immunity. Biology and Philosophy 21: 235-252.

von Uexkull, Jakob (2010) A Foray into the Worlds of Animals and Humans. Minneapolis, MN: University of Minnesota Press. 
Samantha Frost is Professor in the Department of Political Science, the Department of Gender and Women's Studies, and the Unit for Criticism and Interpretive Theory at the University of Illinois, Urbana-Champaign. While publishing a range of work on Thomas Hobbes's materialism, Frost also co-edited with Diana Coole New Materialisms: Ontology, Agency, and Politics (Duke University Press, 2010) and authored Biocultural Creatures: Toward a New Theory of the Human (Duke University Press, 2016). From 2016 to 2019, she was the Faculty Fellow directing the IPRH-Mellon Biohumanities Research Initiative funded by the Andrew W. Mellon Foundation and hosted by the Illinois Humanities Research Institute. Currently, Frost is a Mellon Collaborative Fellow at the University of Chicago's Gray Center for Arts and Inquiry, collaborating with artists Amber Ginsburg and Sara Black on a project called 'Untidy Objects'. In addition to composing a manuscript tentatively called Attentive Bodies, she is collaborating with historians Renisa Mawani and Antoinette Burton on a scholarly collection called Biocultural Empires.

Tomoko Tamari is a Senior Lecturer in Sociology at the Institute for Creative and Cultural Entrepreneurship, Goldsmiths, University of London. She is managing editor of Body \& Society and has published 'Body Image and Prosthetic Aesthetics' (Body \& Society 23(1), 2017). She is currently working on the following areas: body image and disability, human perception and the moving image, probiotics and immunity. 
